\title{
An Aortic Pseudoaneurysm following Bentall Procedure
}

\author{
Yavuzer Koza, MD ${ }^{1 *}$, Uğur Kaya, MD², Muhammed Hakan Tas, MD ${ }^{1}$, Ziya Simsek, MD ${ }^{1}$ \\ ${ }^{1}$ Department of Cardiology, Ataturk University Faculty of Medicine, Erzurum, Turkey; and ${ }^{2}$ Department of Cardiovascular Surgery, \\ Ataturk University Faculty of Medicine, Erzurum, Turkey
}

\begin{abstract}
We describe a rare case of an ascending aortic pseudoaneurysm detected incidentally at coronary angiography in a 64-year-old man with a history of a Bentall procedure 8 years previously. The patient underwent reoperation, with longitudinal opening and cleaning of the aortic pseudoaneurysm and graft repair of the defect. This report highlights the insidious late onset of pseudoaneurysm and the importance of its detection and treatment. Copyright $\odot 2014$ Science International Corp.
\end{abstract}

\section{Key Words}

Aortic pseudoaneurysm • Bentall procedure

\section{Case Presentation}

A 64-year-old male patient was admitted to our hospital with the diagnosis of acute coronary syndrome. Eight years before this presentation, he had undergone coronary bypass surgery with additional Bentall procedure for a dilated aortic root $(5.6 \mathrm{~cm})$ and severe aortic regurgitation, using a St. Jude Medical (St. Paul, Minnesota, USA) composite graft. Physical examination revealed blood pressure of 130/70 $\mathrm{mm} \mathrm{Hg}$, a regular pulse of 82 beats/minute and a systolic murmur of 2/6 with normal mechanical valve sounds in the aortic area. Transthoracic echocardiography showed a bileaflet prosthetic valve in the aortic position with a peak gradient of $20 \mathrm{~mm} \mathrm{Hg}$ and mildly reduced left ventricular function with an estimated

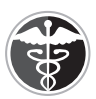

Fax +1 2037853346

E-Mail: aorta@scienceinternational.org http://aorta.scienceinternational.org (c) 2014 Aorta.

Published by Science International Corp. ISSN 2325-4637

Accessible online at:

http://aorta.scienceinternational.org ejection fraction of $45 \%$. The ascending aorta was 58 $\mathrm{mm}$ across the pseudoaneurysm. At coronary angiography all bypass grafts [aorta-right coronary artery (RCA) and aorta-diagonal artery, saphenous vein grafts] except the left internal mammary artery-left anterior descending artery (LAD) were patent. Aortic root angiography showed an aortic pseudoaneurysm originating from the RCA-saphenous graft proximal anastomosis site in the proximal ascending aorta. A contrast-enhanced multidetector computed tomography revealed a $26 \times 14 \mathrm{~mm}$ pseudoaneurysm in the front of the ascending aortic graft just above the right coronary anastomosis (Figure 1A-1D).

On the basis of these findings, the patient underwent reoperation, with longitudinal opening and repair of the aortic pseudoaneurysm. At operation an anastomosis dehiscence between the aortic graft and native aorta with a $5 \mathrm{~cm}$ defect was observed and the defect was repaired with an interposition Dacron graft. An aortaLAD saphenous graft anastomosis was also performed. The postoperative clinical course was uneventful.

\section{Conflict of Interest}

The authors have no conflict of interest relevant to this publication.

\section{Comment on this Article or Ask a Question}

*Corresponding author:

Yavuzer Koza, MD

Department of Cardiology

Ataturk University Faculty of Medicine

Yakutiye, Erzurum, Turkey 25100

Tel: +90 44223185 21, Fax: +90 44223613 01, E-Mail: yavuzerkoza@hotmail.com 

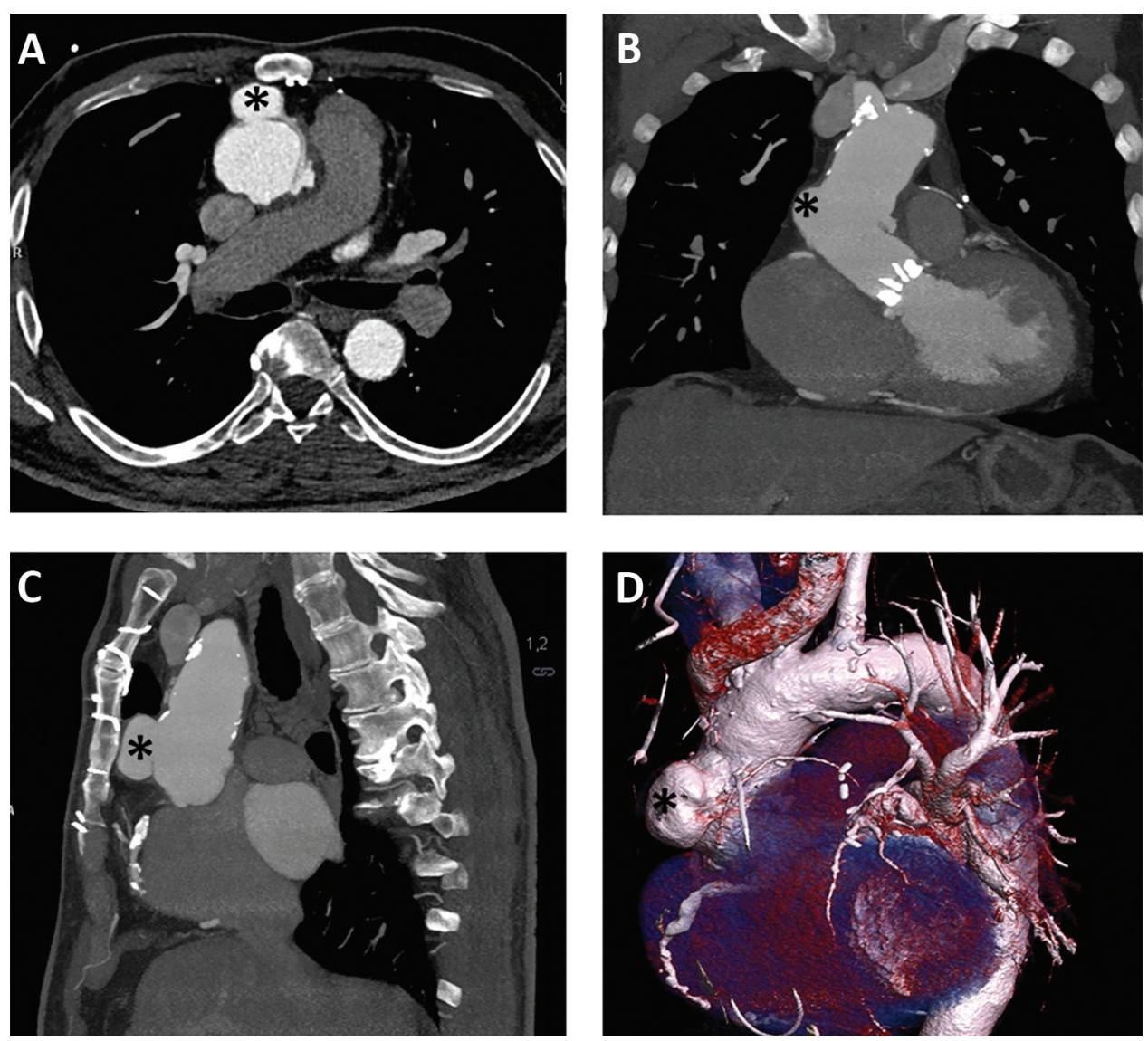

Figure 1. A multidetector computed tomography showing a pseudoaneurysm in the front of the ascending aortic graft just above the right coronary anastomosis. A. Axial section. B and C. Sagittal section. D. Three-dimensional volume rendered image of the pseudoaneurysm.

Cite this article as: Koza Y, Kaya U, Tas MH, Simsek Z. An Aortic Pseudoaneurysm following Bentall Procedure. Aorta 2014;2(5): 200-201. DOI: http://dx.doi.org/10.12945/j.aorta.2014.14-030 